\title{
Ciência, senso comum e revoluções científicas: ressonâncias e paradoxos"
}

\author{
Marivalde Moacir Francelin \\ Mestre em biblioteconomia e ciência da \\ informação pela PUC-Campinas. \\ E-mail:mfrancelin@yahoo.com.br
}

\section{Resumo}

Revisa alguns aspectos da constituição do conhecimento científico, como, por exemplo, sua definição, sua relação com a filosofia, com a religião e com o mito; segundo, descreve algumas características de eventos que se desenvolveram e ainda se desenvolvem a partir de novos conceitos em torno da própria ciência, tais como o (novo) senso comum e algumas discussões (Thomas Kuhn e Karl Popper) sobre as revoluções científicas. Estabelece que a gênese científica relaciona-se às manifestações cotidianas, modificandose e distinguindo-se em suas múltiplas interpretações.

\section{Palavras-chave}

Ciência; Filosofia da ciência; Senso comum; Revoluções científicas; Thomas Kuhn; Karl Popper; Conhecimento.

\section{Science, common sense and scientific revolutions: resonances and paradoxes}

\section{Abstract \\ The objective of this paper is to revise some aspects of the constitution of scientific knowledge as, for example, its definition, its relation in regard to philosophy, religion and myth. Another objective is to describe some characteristics of events that have been developed and are still being developed from new concepts about science itself, such as, (new) common sense and some (Thomas Kuhn and Karl Popper) discussion on the scientific revolutions. It points out that scientific genesis is related to daily manifestations, modifying itself and distinguishing itself in its multiple interpretations.}

\section{Keywords}

Science; Philosophy of science; Common sense; Scientific revolutions; Thomas Kuhn; Karl Popper; Knowledge.

\footnotetext{
* Esse texto foi elaborado a partir de uma das seções da dissertação de mestrado defendida pelo autor em 2004.

${ }^{* *}$ NIETZSCHE, Friedrich Wilhelm. Humano, demasiado humano: um livro para espíritos livres. São Paulo: Companhia das Letras, 2004.
}

\begin{abstract}
Relação com a ciência. - Não têm real interesse por uma ciência aqueles que começam a se entusiasmar por ela somente depois que nela fazem descobertas.
\end{abstract}

(Nietzsche) $^{* *}$

\section{INTRODUÇÃO}

Uma das características singulares da ciência na contemporaneidade é a sua flexibilidade em relação a alguns aspectos antes considerados indesejáveis, em função do excesso pragmático e do isolamento disciplinar. Porém, pode-se notar que esses são apenas alguns pontos salientes no âmbito científico. Vários outros conjuntos de relações, conceitos e interpretações poderiam ser estabelecidos a partir de temáticas como ciência, senso comum e revoluções científicas. Discussões como essa tornamse quase que intermináveis. São sugestivos os distintos pontos abordados em torno dos temas. $\mathrm{O}$ que se chama de "estatuto científico" parece tomar uma forma diferente nesse sentido, pois participa da incerteza que compõe os meandros científicos. São essas incertezas que se tenta abordar no presente texto.

Inicialmente, tentou-se expor alguns conceitos sobre ciência, senso comum e revoluções científicas, para, em um segundo momento, relacionar algumas discussões sobre os temas. Procurou-se destacar o papel da ciência enquanto agente em diversas esferas do conhecimento, bem como sua relação com outros tipos de saberes e eventos.

O contexto científico é variável e, sem dúvida, pode receber interferência do ambiente tanto local quanto global. Porém, essas tais influências podem ser recebidas $\mathrm{e}$, principalmente, entendidas de diversas maneiras em um mesmo evento e por um mesmo observador. Exemplo disso são as revoluções científicas que passaram por enfoques distintos em função do debate aprofundado e prolongado entre Thomas Kuhn e Karl Popper.

Na ciência não foi, não é e, provavelmente, não será diferente. Nesse sentido, o debate prende-se à ciência e tenta mapear uma espécie de gênese científica, justificando a necessidade de uma aproximação com o senso comum. Assim, reúnem-se os componentes que permeiam ambiente e espírito humanos em suas manifestações cotidianas, em detrimento dessa espécie de gênese científica. 


\section{RESSONÂNCIAS CIENTÍFICAS*}

A questão mais difícil de ser respondida ao se tratar da temática "ciência" é a que se relaciona com a sua definição. Como definir ou conceituar ciência? Essa pergunta permeia grande parte do itinerário bibliográfico no campo das ciências, mas nem sempre é respondida. Freire-Maia (1998) diz que raramente os filósofos da ciência se propõem a definir ciência. Existem, segundo o autor, três motivos para essa recusa: o primeiro reside no fato de toda definição ser incompleta (sempre há algo que foi excluído ou algo que poderia ter sido incluído); o segundo, na própria complexidade do tema; e o terceiro, justamente na falta de acordo entre as definições (FreireMaia, 1998, p.24).

Como alternativa, Freire-Maia (1998) propõe colocar "de lado" as fundamentações epistemológicas e, a partir do uso de princípios elementares, proceder a uma "tosca" definição de ciência que contemplaria um "[...] conjunto de descrições, interpretações, teorias, leis, modelos etc., visando ao conhecimento de uma parcela da realidade [...]", através de uma "metodologia especial", no caso, a metodologia científica (Freire-Maia, 1998, p.24).

É quase unânime a noção de que a ciência "[...] é um vocábulo enganosamente amplo, que designa grande diversidade de coisas diversas, embora relacionadas entre si" (Merton, 1979, p.38). Portanto, "[...] falar do significado da ciência levanta imediatamente numerosas questões, umas relativas à palavra ciência e outras relativas à palavra significado" (Roqueplo, 1979, p.140).

Segundo Morais (1988), a ciência é "[...] mais do que uma instituição, é uma atividade. Podemos mesmo dizer que a "ciência' é um conceito abstrato." O que se conhece "concretamente", continua o autor, são os cientistas e o resultado de seus trabalhos. "O cientista contemporâneo sabe bem que nada há de definitivo e indiscutível que tenha sido assentado por homens" (Morais, 1988, p.24). A ciência não se reduz a experimentos, pelo contrário, é extremamente abrangente e complexa. O experimento científico como critério de cientificidade é ponto fundamental para o desenvolvimento das ciências exatas e biológicas ou da natureza, mais bem representadas pela física e pela biologia (especialmente através de seus desdobramentos disciplinares nas últimas décadas do século XX). Porém, esse mesmo cientificismo não é partilhado pelas disciplinas que compõem as chamadas ciências humanas e sociais**.

\footnotetext{
"Sobre a discussão em torno do "conhecimento filosófico" e do possível "reducionismo" da filosofia à ciência, ver Granger (1989). Em filosofia da ciência, ver Geymonat [s.d.].
}

O pensamento científico não se forma nem se transforma apenas pelo experimento, pelo contrário, anterior à práxis científica estão a idéia, o pensamento, o "conhecimento do conhecimento", a filosofia da ciência, que trazem à tona as discussões em torno da epistemologia, dos paradigmas, da ética, da moral, da política, enfim, características relacionadas e inter-relacionadas ao desenvolvimento do conhecimento e aos possíveis desdobramentos e conseqüências que possam trazer.

Whitehead (1946) lembra que a filosofia é a mais "eficaz pesquisa intelectual.” Ela é a responsável pela construção de "[...] catedrais antes que os trabalhadores tenham removido uma pedra, e as destrói antes que os elementos tenham esboroado as suas arcadas" Há sempre um pensamento, até um instinto que precede a prática, o ato material. Esse processo não é necessariamente imediato, pois a "[...] filosofia trabalha devagar. Os pensamentos dormem longo tempo; quase imediatamente depois a humanidade sente que se incorporou a si mesma em instituições" (Whitehead, 1946, p.7-8). Para Whitehead (1994), a filosofia está em constante contato com a "humanidade" e, conseqüentemente, com os setores das sociedades que compõem essas "instituições". Nesse caso, filosofia e ciência se aproximam para que o pensamento científico, por meio de uma filosofia conciliadora, constitua-se a partir de uma "harmonização" das ciências. Portanto, a "[...] filosofia não é uma das ciências com seu próprio reduzido esquema de abstrações, que aperfeiçoa e melhora. É a visão geral das ciências com o objetivo de as harmonizar e completar." (Whitehead, 1946, p.103). Já é, segundo Whitehead (1994), uma resposta satisfatória dizer que a filosofia da ciência é responsável pelo "[...] estudo das relações entre os diferentes setores do conhecimento." Porém, o autor lembra que esse estudo pode não só ser dirigido às relações, mas também à falta de relações entre as disciplinas científicas. Ambas, relações e falta de relações disciplinares, são importantes para a filosofia da ciência. "Não é toda e qualquer relação entre as ciências que participa da filosofia das mesmas." Ou seja, muitas disciplinas podem ter pontos em comum, mas não apresentarem nenhum nível de relação ou comunicação. Whitehead (1994) propõe um princípio básico a todas as ciências ou um "conceito unificador". É a filosofia da ciência que tem como função "[...] expressar explicitamente as características unificadoras que permeiam este complexo de pensamentos

\footnotetext{
** O sentido dado ao termo cientificismo, no presente contexto, procura apenas relacioná-lo às ferramentas e metodologias utilizadas pelas ciências chamadas, em determinados momentos, de duras. O desenvolvimento dessas ciências depende, em parte, das condições de abordagem e manipulação de seus objetos de pesquisa, característica de difícil implementação nas ciências humanas e sociais. Por isso a necessidade de desenvolver metodologias próprias que possibilitem a compreensão de seus objetos de pesquisa em suas complexidades, afastando-se de vez das "caras" premissas positivistas estabelecidas, em outros momentos, por essas ciências.
} 


\section{Marivalde Moacir Francelin}

e conferem-lhe a condição de ciência." Portanto, a filosofia da ciência "[...] concebida como um objeto de estudo - é o esforço de representar todas as ciências como uma única ciência, ou - em caso de insucesso - a confutação de tal possibilidade" (Whitehead, 1994, p.5-7).

Bachelard (1991) propõe um "pluralismo filosófico" para caracterizar a filosofia das ciências, pois entende que só é possível abordar "experiência e teoria", em seus variados níveis de maturidade, por meio de uma filosofia que acompanhe essa multiplicidade. $\mathrm{O}$ autor define a filosofia das ciências como uma filosofia "dispersa" e "distributiva". Assim, "[...] o pensamento científico surgir-nos-á como um método de dispersão bem ordenado, como um método de análise aprofundada, para os diversos filosofemas massivamente agrupados nos sistemas filosóficos..." A análise do pensamento científico mediante de uma filosofia dispersa vai ao encontro da própria constituição científica, que, de maneira alguma, forma-se a partir de um conglomerado ordenado. É por isso que Bachelard (1991) diz que os "[...] diferentes problemas do pensamento científico deveriam, pois, receber diferentes coeficientes filosóficos" (Bachelard, 1991, p.14-15).

Deve-se lembrar que nem sempre a filosofia e as ciências estiveram em lados opostos. Segundo Moles (1971), filosofia e conhecimento científico estavam localizados na linha da filosofia natural. "Nem Platão nem Bacon separavam o 'amor à sabedoria' da posição do homem no Universo e do estudo estrutural deste" (Moles, 1971, p.3). A ruptura ocorreu a partir do Renascimento, no momento em que a filosofia começou a tomar um caráter mais abrangente, "[...] englobando até a ética individual e social e as partes mais subjetivas de reflexão do homem sobre si mesmo" (Moles, 1971, p.4). Por sua vez, a ciência tornava-se cada vez mais específica e operacional, criando para si um mundo próprio, passível de ser explicado, experimentável e dominável. Essa estrutura excluía quase que totalmente os sentidos filosóficos de mundo. Para Moles (1971), o "cientificismo" constituía-se como movimento contrário à filosofia, "[...] considerando que toda reflexão do homem sobre seu lugar no mundo é devaneio inútil e impotente [...]", ou seja, não se necessitava de uma filosofia, pois a ciência possuía as respostas para "todos" os problemas e, "[...] se ela não os resolve hoje, deve resolvê-los amanhã" (Moles, 1971, p.4). Isso demonstra a crença na ciência. Eliminando-se algumas características fundamentais do cotidiano humano, como mito e crença, a ciência toma-lhes o lugar na tentativa de tudo explicar, de tudo dominar.

A partir de finais do século XIX e início do século XX, com a "nova" re(evolução) científica, teve início uma revisão dessa posição com relação à filosofia, ou seja, a concepção de verdade absoluta começa a ser posta em questão devido às lacunas deixadas e que não poderiam ser preenchidas apenas pelas pressuposições científicas modernas. Ao se depararem com inconsistências nas concepções de unicidade de mundo, concretude e solidez em suas soluções, os "[...] pesquisadores se viram levados, quase coagidos, a examinar os postulados do determinismo [...]". A crença na verdade absoluta "[...] cedeu lugar a uma concepção mais idealista das relações entre mundo das sensações e mundo construído pela teoria científica" (Moles, 1971, p.5).

Pode-se dizer que, nesse momento, refez-se a relação entre ciência e filosofia, estabeleceu-se uma espécie de teoria científica, construída e constituída pelo fato de o cientista dar-se conta de que sua visão linear e mecanicista de mundo não era nem suficiente nem adequada para tratar dos problemas levantados pelo próprio meio científico.

Alguns eventos podem ser enumerados, como, por exemplo, "[...] o desenvolvimento da Teoria da Relatividade e da Microfísica, o enunciado do princípio de complementaridade de Bohr que encetaram de maneira nítida essa reunião da ciência e da metafísica [...]" (Moles, 1971, p.5). Nesse sentido, Moles (1971) descreve três níveis de desenvolvimento da ciência do século XIX até o início do século XX. São eles: a ciência do certo que, como a expressão já indica, está relacionada à criação, à construção de uma ciência exata, verdadeira, que possuísse em si as qualidades de um conhecimento unívoco e acabado; a ciência do provável, crê em um mundo de probabilidades, abre-se às possibilidades para a busca do conhecimento científico; e a ciência do percebido, que, baseada na concepção schopenhaueriana, constrói uma visão de mundo a partir de uma representação (Moles, 1971 p.6-7).

A religião e a crença (no sentido de acreditar em algo) foram os caminhos utilizados durante séculos pela humanidade na busca de respostas às suas perguntas e aflições. Como afirma Morin (1999b), "[...] durante muito tempo o fundamento em filosofia era Deus, e mesmo nas ciências, pois Newton ainda se referia a Deus. Foi Laplace que excluiu Deus do cosmos e do domínio científico" (Morin, 1999b, p.21). O que se pode dizer, portanto, é que a ciência, ao longo do tempo, também foi se distanciando da crença religiosa, estruturando-se enquanto conhecimento autônomo e independente. Segundo Chrétien (1994), a ciência substituiu a religião e eliminou o obscurantismo sobre os fenômenos mitológicos da história, colocandose no lugar da religião e da história, ou seja, pregando a sua mística e a sua mitologia.

A racionalidade no processo histórico do Ocidente, segundo Chauí (1996), tenta, pelo determinismo, descrever 
por completo os "[...] fenômenos naturais e humanos, oferecendo a definição dos seres e as leis necessárias de suas relações [...]". O que a razão quer é o controle dos eventos cotidianos e o banimento do indeterminismo, ou seja, a "[...] racionalidade trabalha no sentido de eliminar o acaso na natureza, a contingência na história e a fortuna na ética e na política” (Chauí, 1996, p.21-22). Nos dias atuais, a racionalidade, como processo determinista, é amplamente criticada. Apesar de, em certo sentido, o irracional estar relacionado ao mundo científico (Granger, 2002), isso não significa um apelo à irracionalidade. A crítica não é voltada à razão, mas ao uso da razão como único caminho para o conhecimento verdadeiro. Sabe-se que as verdades podem ser provisórias, e uma das funções da racionalidade é construir hipóteses que sustentem essas verdades, ao mesmo tempo em que, pela mesma via, desconstroem-se essas hipóteses e as verdades chamadas provisórias são substituídas. "[...] hoje vemos as ciências aceitarem sua dispersão... A ciência opera com o provável, isto é, com o possível submetido a cálculos" (Chauí, 1996, p.22).

No século XX, a crença no experimento, no reproduzível, no dominável e compreensível entra em conflito com ela mesma, pois "[...] o desabamento conjunto da substancialidade da matéria e do determinismo clássico, em nível subatômico, faz surgir um enigma e um mistério sobre os quais se precipitou o espiritualismo [...]" (Morin, 1999a, p.81). Da mesma forma, Chrétien (1994) lembra que a sociedade necessita de mitos para entender e relacionarse no cotidiano, ou seja, para "[...] fundamentar sua identidade e justificar suas prescrições, valores e relações entre seus membros" (Chrétien, 1994, p.13). O mito pode ser compreendido como necessário para a construção no imaginário popular daquilo que eles não poderiam ter na realidade, ou seja, "[...] o mito geralmente põe em cena deuses e heróis, demiurgos das origens, que lançam as bases da nova ordem. Ele retraça sua epopéia lendária que fixa, no imaginário coletivo, os signos e modelos que postulam os procedimentos comuns de significado e comunicação." Assim, pode determinar os "[...] ritos, as regras do jogo social e os paradigmas sobre os quais se modulam os comportamentos" (Chrétien, 1994, p.13). Com a crise da razão, “[...] os humanos reencontraram um meio para repor aquilo que a teoria havia substituído ao nascer: os mitos, os fundamentalismos religiosos. Mitologias e religiões ocupam hoje o lugar vazio deixado pela razão" (Chaul, 1996, p.22).

Esse imaginário faz parte da condição do viver e do sobreviver humano. A sociedade está intimamente ligada e, muitas vezes, estruturada sobre ou ao redor de valores míticos, de crenças e de dogmas que podem ser, em determinadas sociedades/comunidades, sinônimos de verdade. O sistema mítico converte-se em ciência. Não que a ciência seja análoga à verdade; porém, no caso do imaginário coletivo, a crença pode levar ao sentimento de se estar diante de uma verdade absoluta. A ciência também pode se converter em mito (Hübner, 1993). Segundo Alves (2000), essa conversão é perigosa, pois "[...] todo mito é perigoso, porque induz o comportamento e inibe o pensamento". O autor diz que essa conclusão é um dos pontos "engraçados (e trágicos)" da ciência. Ao crer-se que alguém está pensando por um determinado grupo, este último exime-se da atividade de pensamento e pode "[...] simplesmente fazer o que os cientistas mandam" (Alves, 2000, p.10).

Se a ciência resolve expulsar esse sistema mítico e tenta assumir seu lugar no imaginário coletivo, pois os "[...] deuses e taumaturgos não mais fazem sucesso na era das ciências e técnicas", o que pode ocorrer são lacunas e a "[...] sociedade não pode funcionar se nela ficam vagos os lugares do poder simbólico" (Chrétien, 1994, p.13). Morin (1999a) traz uma explicação que corrobora o que diz Chrétien (1994). Acredita que o mito, no século XX, "[...] tomou a forma da Razão, a ideologia camuflou-se de ciência, a Salvação tomou forma política garantindose certificada pelas Leis da História." Além do mais, é nesse século que o "[...] messianismo e niilismo se combatem, entrechocam-se e produzem-se um ao outro, a crise de um operando a ressurreição do outro" (Morin, 1999a, p.15-16).

O que se tenta agora é um certo tipo de restauração a partir do próprio pensamento, concomitantemente ao que se chama de revoluções científicas. Para Morin (2002), foram duas as revoluções científicas responsáveis pela preparação da "reforma do pensamento". A primeira está relacionada à física quântica, que, grosso modo, desencadeou o "[...] esboroamento de toda idéia de que haveria uma unidade simples na base do universo [...]", pôs em dúvida o sentido dogmático em torno do determinismo e introduziu o conceito de incerteza no meio científico. A segunda revolução está relacionada ao princípio não reducionista para o pensamento científico, tão marcante, segundo Morin (2002), no século XIX. “[...] há uma ressurreição das entidades globais, como o cosmo, a natureza, o homem [...]", passando a integrarem um amplo sistema de relações e complexidade (Morin, 2002, p.89-90).

\section{POSSIBILIDADES EM TORNO DO SENSO COMUM}

Bases conceituais podem ser consideradas indispensáveis para qualquer estudo ou discussão epistemológica em determinada disciplina. Os conceitos que formam tal base podem ser construídos ao longo do tempo por novas e 


\section{Marivalde Moacir Francelin}

antigas disciplinas, passando, primeiramente, pelo crivo da comunidade científica, na qual expostos a críticas que consolidarão ou não a sua utilização.

Os conceitos nascem no cotidiano (senso comum) são apropriados pelo meio científico e tornam-se científicos ao romperem com esse cotidiano, com esse senso comum. Segundo Cotrim (2002), o "[...] vasto conjunto de concepções geralmente aceitas como verdadeiras em determinado meio social recebe o nome de senso comum" (Cotrim, 2002, p.46).

Em seu livro Um discurso sobre as ciências, Boaventura de Souza Santos propõe um novo senso comum, em que a "[...] distinção hierárquica entre conhecimento científico e conhecimento vulgar tenderá a desaparecer e a prática será o fazer e o dizer será a filosofia prática" (Santos, 2002, p.10). Depois dele, foram publicados Introdução a uma ciência pós-moderna e A crítica da razão indolente: contra o desperdício da experiência, em 2000 e 2001, respectivamente. Santos expõe nessas três obras a crise ou as crises dos paradigmas da ciência moderna e reflete sobre uma nova estrutura científica pós-moderna. Nesse sentido, o autor diz que a ciência moderna "construiu-se contra o senso comum", considerando-o "superficial, ilusório e falso" e a ciência pós-moderna vem para reconhecer os valores ("virtualidades") do senso comum que enriquecem a "nossa relação com o mundo", ou seja, o senso comum também produz conhecimento, mesmo que ele seja um "conhecimento mistificado e mistificador". "[...] mas, apesar disso e apesar de ser conservador, tem uma dimensão utópica e libertadora que pode ser ampliada através do diálogo com o conhecimento científico" (Santos, 2002, p.56).

Santos (2002) justifica a aproximação do conhecimento do senso comum ao conhecimento científico com a da descrição de algumas características do próprio senso comum, tais como causa e intenção; prática e pragmática; transparência e evidência; superficialidade e abrangência; espontaneidade; flexibilidade; persuasão (Santos, 2002, p.56). O autor afirma que é necessário uma ruptura epistemológica inversa à que ocorrera na ciência moderna, ou seja, em vez de distanciar-se do senso comum para atingir um nível qualitativo para a pesquisa científica, agora é necessário aproximar esse conhecimento o máximo possível do conhecimento do senso comum, pois o "[...] conhecimento científico pós-moderno só se realiza enquanto tal na medida em que se converte em senso comum." Afirma ainda que a ciência pós-moderna, ao "sensocomunicar-se", não "[...] despreza o conhecimento que produz tecnologia, mas entende que, tal como o conhecimento se deve traduzir em autoconhecimento, o desenvolvimento tecnológico deve traduzir-se em sabedoria de vida" (Santos, 2002, p.57).
Como boa parte dos pensadores pós-modernos, Santos (2000) não deixa de mencionar a influência exercida em sua obra pelo pensamento bachelardiano e, seguindo o pensamento deste último, diz que o conhecimento científico somente é possível mediante o rompimento com o conhecimento vulgar, com o senso comum. A ciência "[...] constrói-se, pois, contra o senso comum, e para isso dispõe de três atos epistemológicos fundamentais: a ruptura, a construção e a constatação" (Santos, 2000, p.31).

Tratando o senso comum como um certo tipo de conhecimento, Santos (2000) o classifica como conservador e fixista, afirmando que a "[...] ciência, para se constituir, tem de romper com essas evidências e com o "código de leitura' real que elas constituem [...]” (Santos, 2000, p.32). Mas, não deixa de vaticinar o "reencontro da ciência com o senso comum", sendo isso possível mediante uma "ruptura com a ruptura epistemológica." Segundo o autor, o senso comum, enquanto conceito filosófico, aparece no século XVII como iniciativa burguesa de combate ao irracionalismo, sendo que a "valorização filosófica do senso comum" esteve atrelada à ascensão da burguesia ao poder, pois ele era considerado "[...] natural, razoável, prudente, um senso que é burguês e que, por uma dupla implicação, converte-se em médio e em senso universal" (Santos, 2000, p.36). Alves (2000) concorda e completa a opinião de Santos (2000), dizendo que o senso comum foi criado por pessoas que se consideravam encontrarse "[...] acima do senso comum, como uma forma de se diferenciarem de outros que, segundo seu critério, são intelectualmente inferiores" (Alves, 2000, p.13).

Porém, estando a burguesia no poder, o "conceito filosófico de senso comum" torna-se "correspondentemente desvalorizado, significando um conhecimento artificial e ilusório". Santos (2000) credita a esse senso comum o nascimento das ciências sociais no século XIX. Elas teriam surgido por meio de um movimento contrário ao senso comum. A relação das ciências sociais com o senso comum tem sido complexa e ambígua por diversos motivos: o primeiro está relacionado a determinadas correntes teóricas que não desejam a ruptura com o senso comum; o segundo diz respeito às correntes que propõem a ruptura, porém "[...] tem várias concepções do senso comum, umas salientando sua positividade, outras sua negatividade." Dessa forma, o senso comum pode ser "[...] o menor denominador comum daquilo em que um grupo ou um povo coletivamente acredita [...]" (Santos, 2000, p.37).

Morais (1988) diz que a aproximação do saber científico ao senso comum parece ser um tanto radical, mesmo sendo "[...] inestimável o valor daquilo que o povo levanta de suas 
experiências cotidianas, pois este é o seu saber. Mais ainda: não se pode negar que é do conhecimento vulgar que parte a atividade científica" (Morais, 1988, p.23). Porém, justifica a separação entre o senso comum e o conhecimento científico, justamente pelo aperfeiçoamento metodológico desenvolvido por este último, ou seja, "métodos especiais que permitiam resultados especiais.” Como exemplo: o sol parece girar ao redor da Terra, e esta não se move, essa é a "[...] maneira como olhamos e vemos o Sol indo de um lado para o outro da Terra" Por esse motivo existem os "métodos especiais de pesquisa". Eles servem para conduzir "[...] nosso pensamento para a conclusão de que é a Terra que gira em torno do Sol, embora não pareça assim (conhecimento científico)" (Morais, 1988, p.23-24).

Em contrapartida, existem processos constantes de revisões e correções feitas pelos cientistas em virtude de entenderem esse processo como parte do desenvolvimento científico, e não como sinal de falência da ciência. "[...] o conhecimento científico abandona seu caráter de 'indiscutível', conferido pela mentalidade cientificista dos séculos XVIII e XIX, mas não abre mão de sua busca de conhecimento genuíno e exato" (Morais, 1988, p.24). Isso se processa por um método que permite a sistematização de dados e fatos que possam comprovar os resultados obtidos. $\mathrm{O}$ senso comum e o conhecimento científico estão relacionados ao cotidiano humano, assim como podem relacionar-se entre si, porém são distintos, e tais distinções devem ser consideradas. Diante desse fato, Morais (1988) sugere que o senso comum, ou "conhecimento vulgar", pode ser designado como "empírico", que "[...] provém da experiência comum das gentes." Diferencia-se do experimento, ou seja, a "[...] vivência nos permite as percepções cotidianas ocasionais e daí se origina a 'Experiência'. Já o experimento (ou experimentação) é aquilo que deve ocorrer segundo um plano de pesquisa." E, como exemplo, associa o experimento ao "trabalho de laboratório". Assim, enquanto a experiência é "[...] a-metódica e assistemática, o experimento é metodicamente provocado e sistematicamente analisado" (Morais, 1988, p.25).

A pesquisa científica tem início no conhecimento vulgar, porém dele se diferencia através de metodologias e princípios que visam a legitimá-la enquanto conhecimento científico. "Nunca será demasiado repetirmos que as investigações da ciência partem de crenças e diferenciações originadas no saber vulgar. Mas, partem daí para a tentativa de ultrapassar as limitações deste saber" (Morais, 1988, p.26). Para Cotrim (2002), essas opiniões são reproduzidas "[...] irrefletidamente no cotidiano, algumas dessas noções escondem idéias falsas, parciais ou preconceituosas. Outras podem revelar profunda reflexão sobre a vida - o que chamamos de sabedoria popular." A caracterização do senso comum não passa, necessariamente, por critérios de verdade ou falsidade, mas sim pela "falta de fundamentação sistemática", ou seja, recebem e emitem opiniões sem saber por que e o que significam. São processos acríticos nos quais um indivíduo concebe um conjunto de informações como conhecimentos, sem saber realmente o que significam, e os utiliza na prática cotidiana como se fossem verdadeiros e definitivos, sendo estes últimos apenas "conhecimentos provisórios e parciais" (Cotrim, 2002, p.47). No meio científico, os conhecimentos também podem ser provisórios e parciais, podem dar lugar a novos conhecimentos que surgem ao longo do tempo através de novas pesquisas. A grande diferença é que no meio científico deve haver plena consciência de que uma pesquisa que leva a um novo conhecimento não é definitiva. O senso comum, portanto, descarta essa premissa, pois as opiniões obtidas podem ser emitidas como verdadeiras e definitivas. A ciência, aparentemente, busca por meio de seu rigor na pesquisa, no debate e crítica de opiniões, afastar-se do senso comum.

\section{POPPER E KUHN: PARADOXOS DAS REVOLUÇÕES CIENTÍFICAS}

Thomas Kuhn e Karl Popper devem ser lembrados como dois dos mais destacados pensadores da ciência do século XX. Ambos deram grande contribuição ao pensamento científico e fomentaram um prolongado debate em torno de suas idéias.

Popper critica a filosofia do positivismo lógico desenvolvida pelo Círculo de Viena. O Círculo de Viena (tendo como seus maiores representantes Wittgenstein, Carnap e Schlick) defendia o princípio do verificacionismo. Qualquer hipótese, para ser científica, tinha de ser considerada "verificável” (Freire-Maia, 1998, p.83).

Não concordando com essa concepção, Popper propõe o que chama de "falseabilidade" ou "falibilismo". O falseacionismo se aproxima mais de um método no qual toda proposição, para ser científica, deve ser falseável. Esse procedimento é a principal característica da filosofia da ciência popperina.

Para Popper, a ciência se desenvolve a partir de revoluções constantes, renovando-se permanentemente. O critério de falseabilidade está associado à idéia de movimentação e rupturas de paradigmas científicos, ao contrário do verificacionismo, que tem como princípio básico a idéia de verdade, portanto algo que se estabiliza em determinado momento; o falseacionismo ou falibilismo não pressupõe uma verdade primeira, mas um enunciado seguido de uma contraprova ou de sua "falseação". A idéia é a de que a ciência ou o conhecimento científico se desenvolve a partir da busca e da tentativa de encontrar lacunas para falsear uma teoria. Nesse caso, os cientistas desenvolveriam teorias (métodos) cada vez mais consistentes e flexíveis, pois 


\section{Marivalde Moacir Francelin}

contariam com o princípio da incerteza e das mudanças de paradigmas. Tais mudanças seriam constantes.

Essa concepção de ebulição de novos modelos na construção científica, prevista na filosofia da ciência popperiana, por meio de "refutações", encontra, no pensamento de outro importante filósofo da ciência, o seu pressuposto de falibilismo ou refutação. Thomas Kuhn, ao contrário de Karl Popper, afirma que a ciência se desenvolve a partir de revoluções científicas que ocorrem em intervalos específicos (geralmente grandes) de tempo. Para Kuhn, a ciência segue um certo tipo de dogmatismo nesses intervalos, pois se comportará e se desenvolverá de acordo com o paradigma vigente. Esse paradigma engloba um conjunto de valores, teorias e métodos que irão influenciar e servir de "modelo" para uma ou várias comunidades científicas.

Com as revoluções científicas, os paradigmas se renovam e os "velhos" paradigmas são substituídos depois de um período de crise dentro da própria ciência. As crises se manifestam a partir de controvérsias ao redor de metodologias, teorias, valores e conceitos no campo científico. Quando surgem novas concepções paradigmáticas, dá-se início a um período de transição. Nesse período há muito o que ser feito, pois a ansiedade pelo novo é muito mais forte do que a tentativa de revigorar o velho paradigma, e este acaba por ser o argumento que lhe é mais desfavorável. Conseqüentemente, as grandes revoluções científicas passaram por períodos de transição variados, e, dessa maneira, seguiram seus respectivos períodos de vigência enquanto paradigmas. Pode-se citar como alguns dos representantes dessas revoluções científicas: Nicolau Copérnico, Galileu Galilei, Isaac Newton, Charles Darwin e Albert Einstein.

Veja-se que as revoluções científicas, quando tratadas por um espírito científico revolucionário e não-revolucionário, tornam-se extremamente complexas. Kuhn (1979a) lembra que os cientistas são dogmáticos ao avaliarem o próprio desenvolvimento científico. A criatividade tão apregoada como necessária e substancial ao recém-cientista é reduzida a manuais e "cartilhas" científicas no momento de qualquer avaliação. Eis um "espírito" revolucionário desativado ou em inércia. Isso não significa que a criatividade esteja relacionada diretamente às revoluções científicas. Indica que podem haver espíritos criativos e potencialmente revolucionários. E é destes que parte a iniciativa para as revoluções científicas. Em vez do enfoque no evento da descoberta em si, propõe-se a análise de um contexto não como mito (Popper, 1999), mas como um importante agregado à construção científica. Portanto, ter-se-ia um panorama científico que se desenvolve a partir de revoluções e de "espíritos" revolucionários, podendo ocorrer de tempos em tempos (Kuhn, 2001), a todo momento (Popper, 1999), ou das duas maneiras concomitantemente.

Questão semelhante foi levantada por Williams (1979), que pergunta a Kuhn e a Popper como saber o que é ciência. A ciência não é planejada estrategicamente. Os cronogramas restringem-se às pesquisas isoladas e, geralmente, correspondem a curtos espaços de tempo. As próprias pesquisas desenvolvem-se independentes umas das outras. Apenas são compartilhadas depois de sua concretização ou a partir de resultados parciais. Dessa maneira, fica difícil saber como se desenvolve a ciência. O cenário científico depende da descrição do cientista. $\mathrm{O}$ cientista descreverá o que achar prudente. Essa prudência deturpará e excluirá muitos eventos importantes do trajeto científico. Esses são problemas de processo científico, mas a definição de ciência está no processo ou além dele?

Nesse caso, Kuhn e Popper "[...] baseiam suas concepções da estrutura da ciência na sua história ...e a história da ciência não pode suportar essa carga por hora." Mesmo porque "[...] não sabemos o suficiente para permitir que se erija uma estrutura filosófica sobre uma história" (Williams, 1979, p.61). Isso quer dizer que tanto Popper quanto Kuhn desenvolveram suas teorias de acordo com a visão que têm da ciência, o que não significa que uma ou ambas tenham encontrado ou possuam, segundo Williams (1979), a essência da ciência. O próprio Kuhn (1979b) diz que nem o seu trabalho nem o de Popper são fundamentados em "[...] generalizações que constituem as teorias aceitas na sociologia e psicologia (e na história?) [...]”, porém refere-se às "[...] observações coligidas por historiadores e sociólogos [...]" como "importantes" à filosofia da ciência" (Kuhn, 1979b, p.291). Essa importância parece estar clara no pensamento kuhniano (Kuhn, 2001, p.11-12).

As posições defendidas por Popper $(1979 ; 1975)$ e por Kuhn (1979b; 2001) estão envoltas, segundo os próprios autores, em mal-entendidos. Popper diz que Kuhn não o "entende" ou o "interpreta mal" (Popper, 1979, p.63). Já Kuhn diz a mesma coisa, não de Popper, mas de Lakatos (1979). Lakatos é seguidor e defensor das idéias de Popper (Chalmers, 1994, p.12), chegando a colocá-lo no mesmo nível de David Hume e Immanuel Kant (Lakatos, 1999, p.151). Portanto, Kuhn, ao criticar ou defender-se do que diz Lakatos, está, de certa maneira, estendendo sua argumentação a Popper. Segundo Feyerabend (1991), Lakatos foi o "[...] único filósofo da ciência que aceitou o desafio de Kuhn [...]" e o combateu em "[...] seu próprio terreno e com as suas próprias armas" (Feyerabend, 1991, p.330).

Pensamentos como esses, aparentemente divergentes em certos aspectos, acabam se encontrando e desenvolvendo 


\section{Ciência, senso comum e revoluções científicas: ressonâncias e paradoxos}

uma quase complementaridade justamente em dois dos aspectos considerados mais importantes da história do pensamento científico: as crises e as revoluções.

\section{CONSIDERAÇÕES FINAIS}

As condições que associam e, ao mesmo tempo, separam conhecimento vulgar ou conhecimento do senso comum do conhecimento científico também parecem estar se modificando devido a novas posturas da comunidade científica, principalmente no âmbito da divulgação científica. Essa aparente transformação atinge diretamente a cultura científica, espera-se que já distante do cientificismo clássico, em quase todas as suas instâncias, ou seja, os processos, procedimentos e produtos científicos são, em certo sentido, disponibilizados ao público especializado (pares) e ao público leigo (senso comum). Uma espécie de tolerância científica parece estar sendo aplicada às teorias e métodos da própria ciência. Pode-se dizer que os campos de conhecimento estão buscando ultrapassar as barreiras que existem entre eles. Ou seja, as relações entre ciência, filosofia, Deus, mito e senso comum são fundamentais, pois estão e até podem ser esses próprios limites.

Considerando-se os conceitos e as distintas e várias teorias que estão na e em torno da ciência, dificilmente crenças, mitos e, especialmente, senso comum poderão ser inteiramente deslocados do seu discurso. Um campo de conhecimento talvez não baste por si só e parece que não constrói conhecimento sem a relação com o oposto. Isso significa que, como já exposto, a ciência necessita do senso comum, que a razão necessita do mito, que a crença pode manifestar-se a partir dos mais rigorosos métodos científicos, que as revoluções dependem de uma suposta verdade, e essa verdade vem do ser humano. Assim, as configurações de verdade, mesmo as científicas e, talvez, principalmente essas, carregam em si as maiores provas e os mais nítidos exemplos de medo, angústia, amor, fé, júbilo filosófico e contemplação na mais alta rigorosidade metodológica e ceticismo científico, pois o espírito científico é metafórico.

Artigo recebido em 31-01-2005 e aceito para publicação em 29-03-2005.

\section{REFERÊNCIAS}

ALVES, Rubem. Filosofia da ciência: introdução ao jogo e suas regras. 2. ed. São Paulo : Loyola, 2000.

BACHELARD, Gaston. A filosofia do não: filosofia do novo espírito científico. Lisboa : Editorial Presença, 1991.

CHALMERS, Alan F. A fabricação da ciência. São Paulo : Unesp, 1994.

CHAUÍ, Marilena. Contingência e necessidade. In: NOVAES, Adauto.
(Org.). A crise da razão. São Paulo : Companhia das Letras, 1996.

CHRÉTtIEN, Claude. A ciência em ação. Campinas : Papirus, 1994.

COTRIM. Gilberto. Fundamentos da filosofia: história e grandes temas. 15. ed. São Paulo : Saraiva, 2002.

FEYERABEND, Paul. Adeus à razão. Lisboa : Ed. 70, 1991.

FREIRE-MAIA, Newton. A ciência por dentro. 5. ed. Rio de Janeiro : Vozes, 1998.

GEYMONAT, Ludovico. Elementos de filosofia da ciência. Lisboa : Gradiva, [199?].

GRANGER, Gilles Gaston. O irracional. São Paulo : Unesp, 2002. . Por um conhecimento filosófico. São Paulo : Papirus, 1989.

HÜBNER, Kurt. Crítica da razão científica. Lisboa : Ed. 70, 1993.

KUHN, Thomas S. A estrutura das revoluções científicas. 6. ed. São Paulo : Perspectiva, 2001.

. Função do dogma na investigação científica. In: DEUS, Jorge Dias de. (Org.). A crítica da ciência: sociologia e ideologia da ciência. 2. ed. Rio de Janeiro : Zahar, 1979a.

Reflexões sobre meus críticos. In: LAKATOS, Imre; MUSGRAVE, Alan. (Org.). A crítica e o desenvolvimento do conhecimento. São Paulo : Cultrix, 1979b.

LAKATOS, Imre. Falsificação e metodologia dos programas de investigação científica. Lisboa : Ed. 70, 1999.

. O falseamento e a metodologia dos programas de pesquisa científica. In: MUSGRAVE, Alan. (Org.). A crítica e o desenvolvimento do conhecimento. São Paulo : Cultrix, 1979.

MERTON, R. K. Os imperativos institucionais da ciência. In: DEUS, Jorge Dias de. (Org.). A crítica da ciência: sociologia e ideologia da ciência. 2. ed. Rio de Janeiro : Zahar, 1979.

MOLES, Abraham Antoine. A criação científica. São Paulo : Perspectiva, 1971.

MORAIS, Regis de. Filosofia da ciência e da tecnologia. 5. ed. São Paulo : Papirus, 1988.

MORIN, Edgar. A cabeça bem feita: repensar a reforma, reformar o pensamento. 6. ed. Rio de Janeiro : Bertrand Brasil, 2002.

- O método 3: o conhecimento do conhecimento. Porto Alegre : Sulina, 1999a.

. Por uma reforma do pensamento. In: PENA-VEGA, Alfredo; NASCIMENTO, Elimar Pinheiro do (Org.). O pensar complexo: Edgar Morin e a crise da modernidade. 3. ed. Rio de Janeiro : Garamond, 1999 b.

POPPER, Karl R. A ciência normal e seus perigos. In: LAKATOS, Imre; MUSGRAVE, Alan (Org.). A crítica e o desenvolvimento do conhecimento. São Paulo : Cultrix, 1979. . A lógica da pesquisa científica. São Paulo : Cultrix/Edusp, 1975. O mito do contexto: em defesa da ciência e da racionalidade. Lisboa : Ed. 70, 1999. 


\section{Marivalde Moacir Francelin}

ROQUEPLO, P. Oito teses sobre o significado da ciência. In: DEUS, Jorge Dias de (Org.). A crítica da ciência: sociologia e ideologia da ciência. 2. ed. Rio de Janeiro : Zahar, 1979.

SANTOS, Boaventura de Sousa. A crítica da razão indolente: contra o desperdício da experiência. 3. ed. São Paulo : Cortez, 2001.

Introdução a uma ciência pós-moderna. 3. ed. Rio de Janeiro: Graal, 2000
. Um discurso sobre as ciências. 13. ed. Porto : Afrontamento,

2002.

WHITEHEAD, Alfred North. A ciência e o mundo moderno. São Paulo : Brasiliense, 1946.

. O conceito da natureza. São Paulo : Martins Fontes, 1994.

WILLIAMS, L. Pearce. Ciência normal, revoluções científicas e a história da ciência. In: LAKATOS, Imre; MUSGRAVE, Alan (Org.). A crítica e o desenvolvimento do conhecimento. São Paulo : Cultrix, 1979. 